\title{
ANGIOGRAPHIC EVIDENCE OF PULMONARY VASOMOTION IN THE DOG
}

\author{
BY \\ JIM C. HIRSCHMAN* AND ROBERT J. BOUCEK \\ From Section of Cardiology, University of Miami School of Medicine, and The Howard Hughes Medical Institute, \\ Miami, Florida, U.S.A.
}

Received May 8, 1962

Pulmonary artery vasomotion is considered to be a factor affecting blood flow through the lungs despite the fact that direct confirmation of pulmonary vascular motion has been difficult to obtain. Indirect evidence has been presented by physiologists using mathematical techniques, involving pressure differences and flow rates.

A more direct approach to the study of pulmonary vasomotion would be by pulmonary angiography. This, however, has its limitations because of the dilution of the contrast material introduced into a peripheral vein or the main pulmonary artery. Such hæmodilution restricts the clarity of the x-ray shadows produced by the small muscular arteries.

Modification in the method of pulmonary angiography obviates most of these problems. This modification consists of a rapid deposition of the opacifying material into a segment of the pulmonary artery via a catheter. Care is taken not to disturb pressure-flow relations by wedging. The contrast material is then viewed by a selective $\mathrm{x}$-ray. The entire sequence is programmed by electronic circuits and is initiated by the $\mathbf{R}$ wave of the electrocardiogram. Arteries can thus be seen at a constant, predetermined millisecond within the cardiac cycle.

Using this technique of angiography, an investigation was made of the vasomotor responses of the distal portions of the pulmonary circulation in the dog. Angiographic records of induced vascular motion were obtained following the individual injection of vaso-active substances, epinephrine, metaraminol, and 5-hydroxytryptamine, and after hypoxia.

\section{Materials AND Methods}

Healthy mongrel dogs were placed under a light plane of anæsthesia with pentobarbital and an $80 \mathrm{~cm}$. No. 6-8 French catheter was inserted into the pulmonary artery by the standard right heart catheterization procedure. The catheter was open-ended with two side holes. Under fluoroscopic control the catheter tip was advanced into a pulmonary artery segment of the right lower lobe, avoiding the wedge position (Fig. 1). Pressures were obtained with a strain-gauge manometer.

After the catheter was positioned, 1-2 ml. of 75\% sodium diatrizoate was injected by a high-speed, hydraulic injector. The programming of dye injection and the subsequent $\mathrm{x}$-ray exposure was controlled by an electronic system described previously (Boucek, Murphy, and Hernandez, 1961).

Standard x-ray equipment was used with medium speed intensifying screens. Film tube distance was 36 in. $(91.4 \mathrm{~cm}$.). The tube was a rotating anode type with a $1.2 \mathrm{~mm}$. focal spot. X-ray settings were $70 \mathrm{KV}, 150 \mathrm{MA}$, with an exposure time of $1 / 60$ second. A sample control arteriogram is shown (Fig. 2).

The first group of dogs received $0.01 \mathrm{mg}$. epinephrine rapidly into the pulmonary artery. Freshly prepared 5-hydroxytryptamine $(0.1 \mathrm{mg}$. $/ \mathrm{kg}$.), henceforth termed serotonin, was infused into the same region in the second group. The metaraminol, in doses of $1 \mathrm{mg}$. diluted to $5 \mathrm{ml}$., was infused into a third group. Epinephrine and serotonin caused a twofold increase in mean PA pressure. Metaraminol elevated the PA pressure to four times control levels.

* Work done during the tenure as post-doctoral N.I.H. research fellow No. HF-11, 345.

Supported in part by Grant \#H-4794 of the National Institutes of Health, and a grant-in-aid from the John A. Hartford Foundation, Inc. 
Fig. 1.-Schematic of the catheter placement and injection. Birdseye tip catheter No. 6 Fr. passed via right heart to pulmonary arterial tree. 1-2 ml. dye by a high-pressure programmed injection.

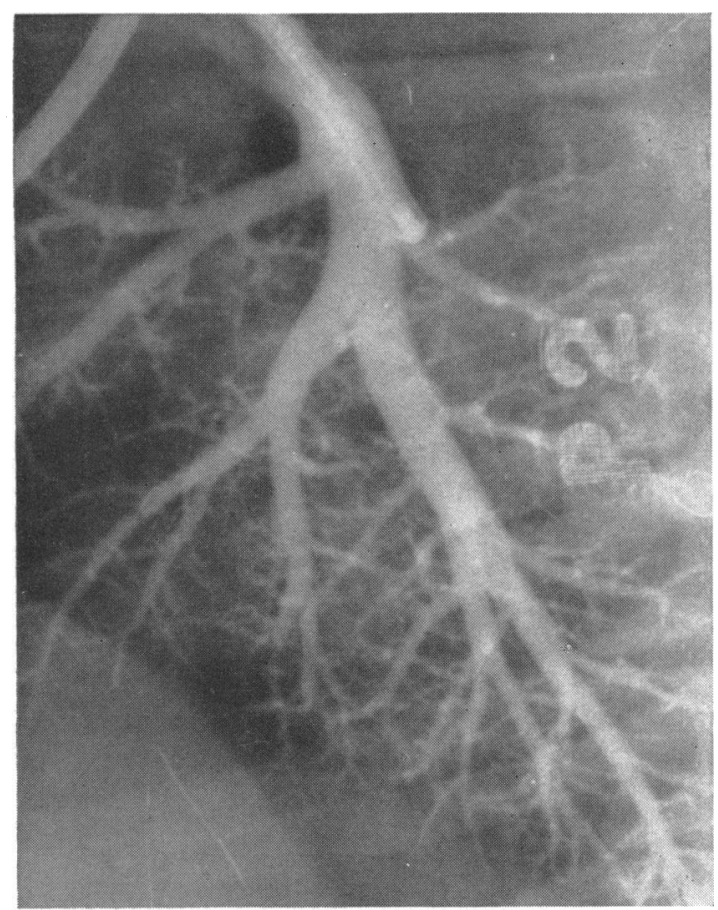

FIG. 2.-Typical arteriogram of the terminal pulmonary vascular pattern. Note the aborization, the smooth contour, and gentle taper of the vessels.

Eucapnic hypoxia followed the use of the respiratory mixture of 10 per cent oxygen in nitrogen: the PA pressure promptly rose (to twice the control) and remained elevated. Upon breathing 100 per cent oxygen, the PA pressure returned to control levels in 15 to 20 seconds. In each experiment, angiograms were obtained at the height of the pulmonary pressor response and after its return.

\section{RESULTS}

Establishment of Optimum Injection and Viewing Times. The variable of injection time was studied by implanting the bolus of dye during different phases of the cardiac cycle. X-ray triggering was fixed at $0.45 \mathrm{sec}$. following the injection. When the injection was made in early systole, maximum visualization of the pulmonary arterioles occurred. Other periods selected for injection yielded less satisfactory viewing. Pulmonary arterial pressure, heart rate, and spontaneous respirations remained constant during the above procedure.

After the optimum injection period was established, the second variable of $\mathrm{x}$-ray timing was tested. Implanting the bolus early in systole and activating the $x$-ray at the end diastole of the same cycle produced the clearest pictures of the arterial pattern.

Once optimum injection and viewing periods were established, implantation of a small bolus of dye (1-3 ml.) gave a clear image of vessels 0.3 to $0.5 \mathrm{~mm}$. in size. The magnification was such that the smallest vessels seen would be approximately 0.2 to $0.3 \mathrm{~mm}$. in diameter.

Effect of Respiration. The respiratory cycle was arbitrarily divided into three periods: active inspiration, expiration, and the resting phase. During inspiration the peripheral arteries were seen (Fig. 3). With expiration, a pooling of the contrast material occurred in the larger arteries with poor filling of the peripheral arteries and arterioles. During the resting state an intermediate 


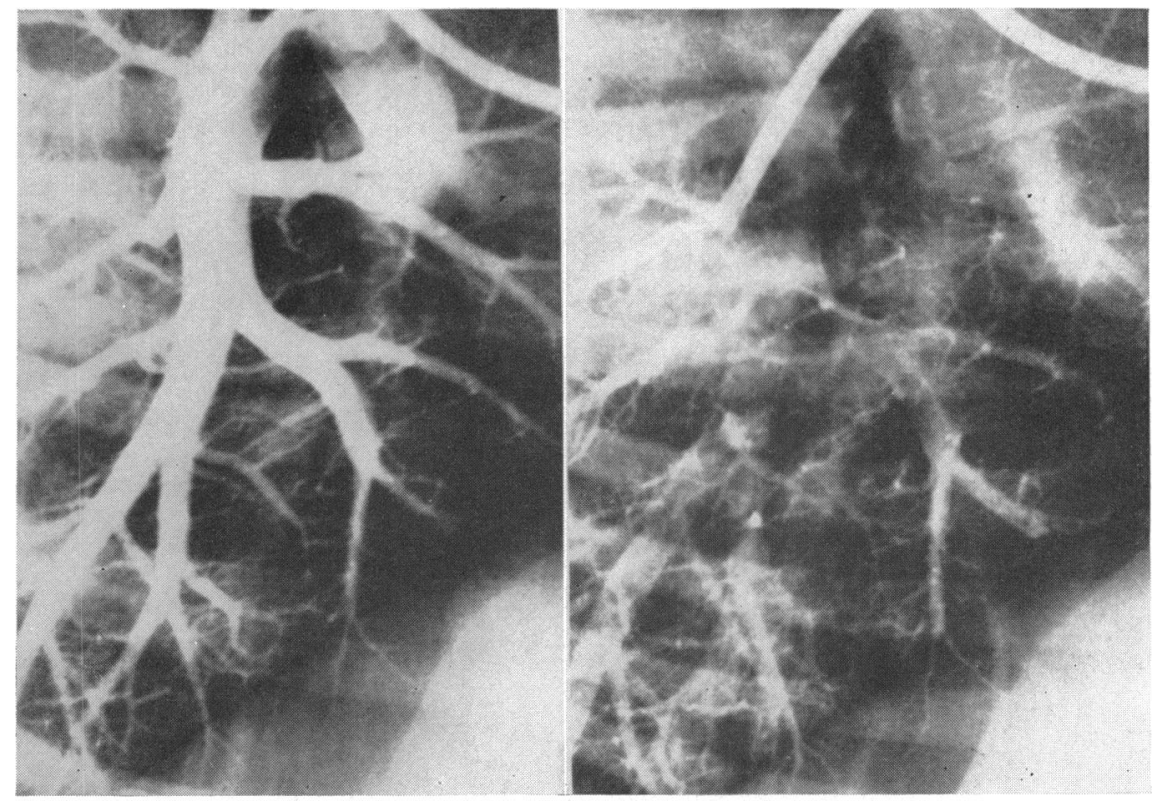

FIG. 3.-Influence of respiration upon the contrast substance transit time. (Expiration on the left and inspiration on the right.) Estimates of the transit time are possible because of the predictable interval of the cardiac cycle for x-ray viewing. Inspiration is associated with a peripheral placement of the contrast material.

filling of the distal arteries and arterioles developed. Visualized small vessels were not altered by the phase of respiration.

Pharmacologically-induced Pulmonary Vasomotion in the Dog. In each of the reported experiments the optimum injection and x-ray viewing times were used at the mid-point between inspiration and expiration. The distal pulmonary arteries were viewed at a constant period in the cardiac cycle.

Epinephrine. The pulmonary arterial systems of 12 dogs were examined following injection of epinephrine. Before the administration of the drug, two angiograms were obtained as the control vascular viewing. Variations in the positioning of the cathode tube, the dog, or the catheter were carefully avoided. After the infusion of epinephrine, respirations increased in depth and rate, and the pulmonary artery pressure and pulse pressure increased. Bradycardia occurred, followed by a slight tachycardia. Angiograms were obtained at different times following the injection of epinephrine. Changes in the arterioles occurred immediately, persisting for 10-15 minutes to a diminishing degree, as the pulmonary arterial pressure declined.

Three types of alterations occurred in the small muscular pulmonary arteries. Bands or collars of constriction appeared at sites of bifurcation of the small arteries, 1-2 mm. in size. Beading occurred along arteries of the 0.5 to $1.5 \mathrm{~mm}$. size. Spiralling developed along previously straight small arteries. In some dogs only one of these three responses could be seen, but in all of the dogs the pulmonary arteries were enlarged (Fig. 4 and 5).

Serotonin caused a rise in pulmonary arterial pressure to a level comparable to the pressor response of epinephrine. Changes in the smaller pulmonary arteries and arterioles were also similar to those described for epinephrine. However, recovery was different, the angiograms returning to the control state within minutes after the compound was discontinued.

Metaraminol. Injections of metaraminol resulted in a rise in PA pressure. The induced 


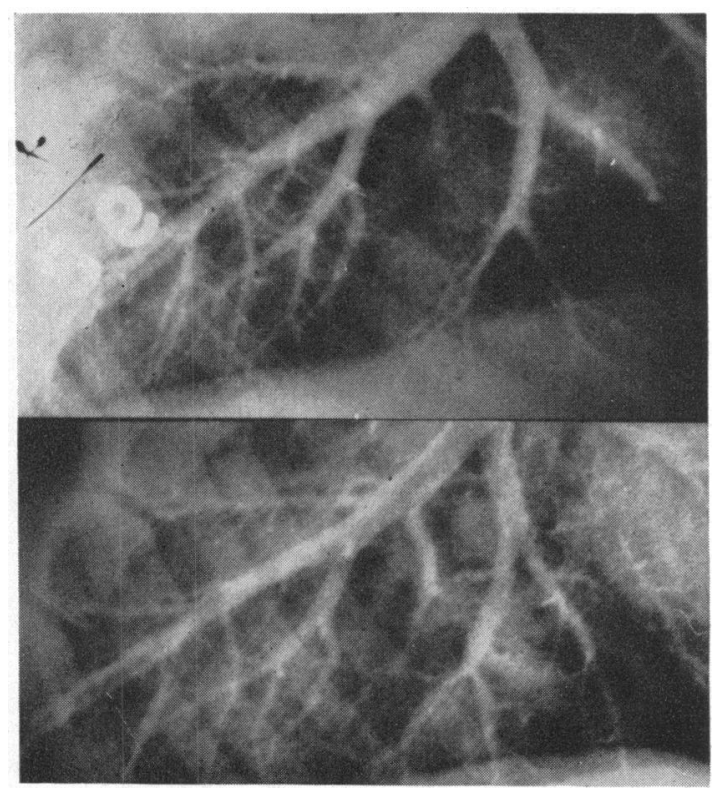

FIG. 4.-Epinephrine response observed in the bottom film when compared to the control, upper film. Collars of constriction particularly at the bifurcation and beading of the distal vessels was observed.

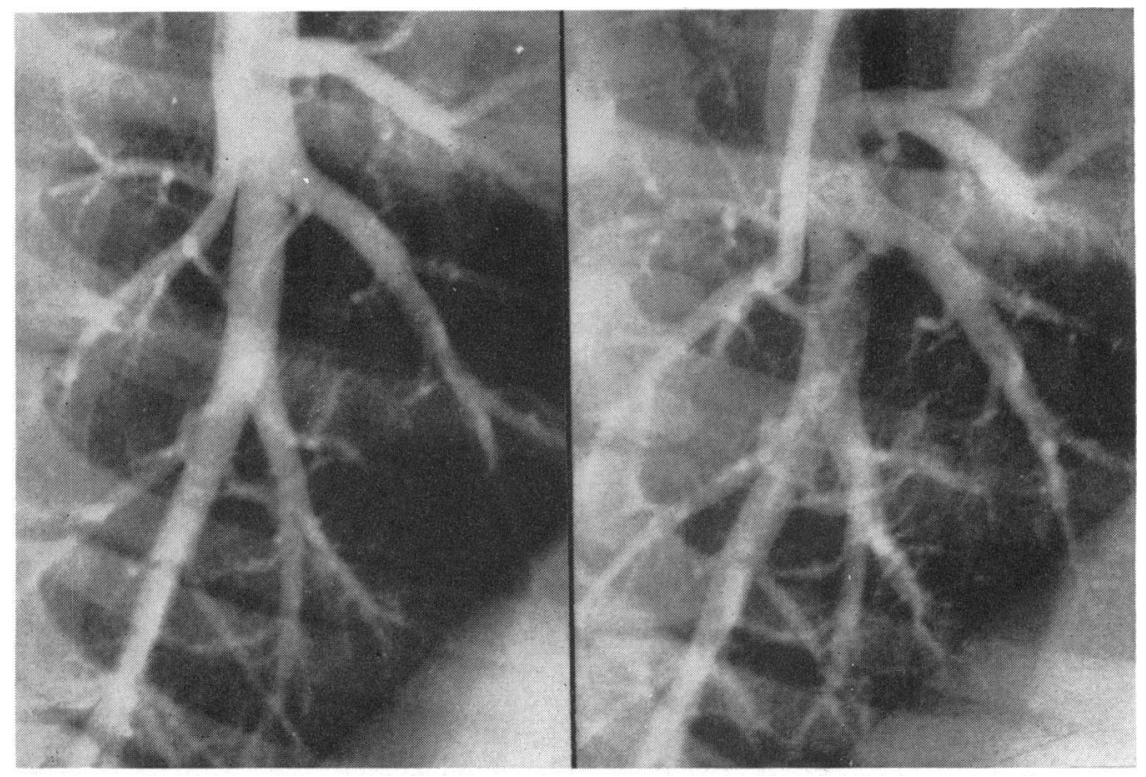

FIG. 5.-Epinephrine response from another dog: control film, left; experimental film, right. Note gnarling and narrowing of the distal vessels with enlargement of the proximal portion of the vessels. 
Fig. 6. - Vasospastic response of metaraminol, principally in the distal arteries with secondary dilatation of the proximal segments.

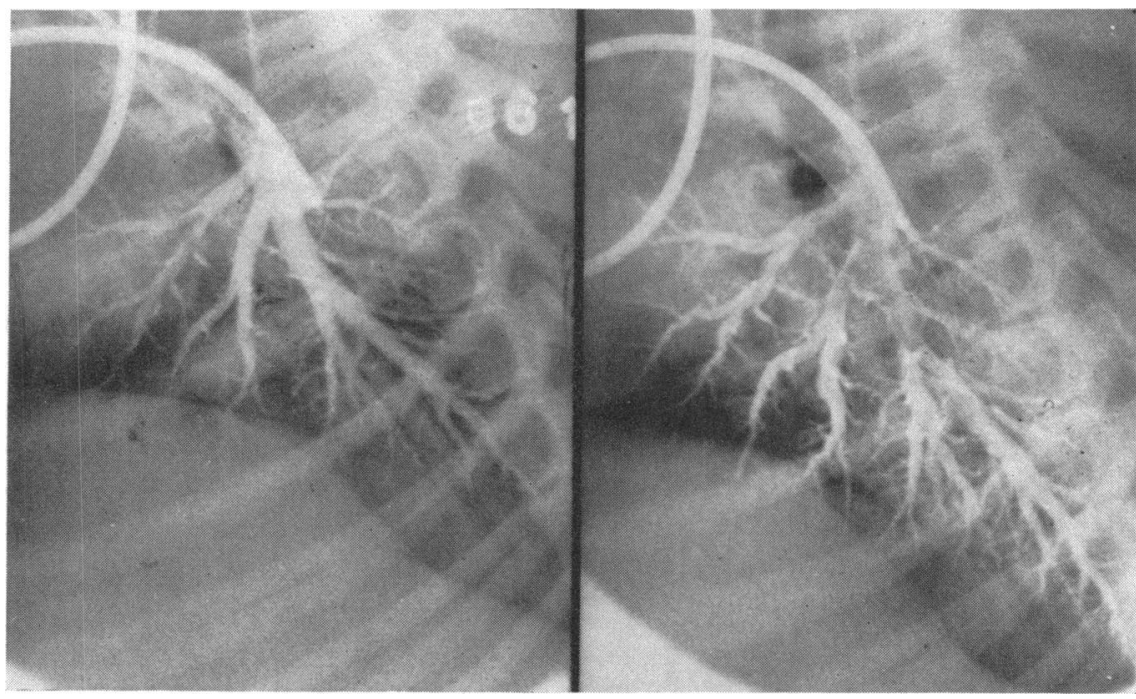

Fig. 7.-Response of the distal arteries following inhalation of 10 per cent oxygen; left, control film; right, experimental film. 
vasomotor effect appeared in the most distal arteries with obliteration of their opacification and secondary enlargement of the proximal pulmonary arteries (Fig. 6).

Hypoxia. Hypoxia increased the pulmonary arterial pressure without affecting the heart rate. Alterations in small arteries resembled the epinephrine changes, including beading, collars of constriction, and spiralling of previously straight vessels. With the breathing of 100 per cent oxygen, PA pressure promptly returned to the control state but angiographic alterations persisted for 10 to 15 minutes.

Although the responses in each of the test situations were qualitatively similar, certain notable differences occurred. Metaraminol caused pulmonary hypertensive and vasospastic responses lasting approximately 30 minutes. With epinephrine, the pulmonary hypertensive response continued for ten minutes after the drug was discontinued, and alterations in the vascular contour persisted even longer. In contrast, the serotonin response disappeared in less than five minutes on the average. Hypoxia induced pulmonary pressor responses similar in magnitude and duration to those of epinephrine and serotonin. Narrowing of longer segments of the pulmonary arteries occurred following hypoxia (Fig. 7).

\section{DisCUSSION}

The muscular arteries range in size from $0.1 \mathrm{~mm}$. up to $1.0 \mathrm{~mm}$. and contain smooth muscle within their media (Heath and Edwards, 1958). Bradford and Dean (1894), investigating the possibility that these vessels might play a role in the control of pulmonary resistance, stimulated the ends of thoracic nerves and recorded the rise in pulmonary pressure. They found that the pressure rise occurred without an increase in heart rate or systemic pressure, and concluded that there must have been pulmonary vasoconstriction. In the years following, however, very little recognition was given to the possibility of pulmonary vasomotor tone. For instance, a 1939 physiology text read, "The tone of these vessels is relatively low so that a rise in left atrial pressure is readily transmitted to the arterial side" (Best and Taylor, 1939). Another text ten years later stated, "The resistance to blood flow in the pulmonary bed can undoubtedly be varied by vasoconstrictor and vasodilator nerves but it is uncertain to what extent the nervous control of the pulmonary bed is exercised under normal conditions or just what its function may be" (Starling and Evans, 1949).

The past decade has seen evidence accumulated for pulmonary vasoconstriction in association with mitral stenosis (Evans, Short, and Bedford, 1957), congenital defects with left-to-right shunt (Patel, Lange, and Hecht, 1958), pulmonary hypertension (Short, 1957), pulmonary embolization (Kabins et al., 1960), serotonin infusion (Rudolph and Auld, 1960), and hypoxia (Fishman et al., 1955). Similarly, acetylcholine, priscoline, and nitroglycerine (Wood et al., 1957; Patel and Burton, 1957; Johnson, Fairley, and Carter, 1959) are believed to lower pulmonary vascular bed "resistance" by their effect on the muscular arteries.

Because of the somewhat inaccessible nature of the pulmonary vascular bed and in hopes of maintaining homeostasis during experiments, indirect methods of assessment have often been used. Such techniques do not provide unequivocal evidence of pulmonary vasomotion. For example, the Poiseuille equation as used holds true only in certain unique situations (Fritts and Cournand, 1959), or at least must be interpreted with caution. The frequently calculated pulmonary vascular resistance may not necessarily provide information regarding the state of contraction, active or passive, of the vessel wall (Shepherd and Wood, 1959).

To study the question of pulmonary vasomotion more directly, plastic casts were made of the pulmonary arterial tree following the injection of pressor agents (Patel and Burton, 1957). With norepinephrine or privine, gnarling and bands of constriction were seen in small arteries of these injected rabbit lungs.

The work described in this paper is the result of in vivo angiography using an unwedged catheter, with electronic programming of dye injection and x-ray triggering. The so-called muscular arteries 
of the 0.1 to $1.0 \mathrm{~mm}$. size were consistently seen. In the intact, lightly anæsthetized dog these vessels are responsive to catechol amines, serotonin, and hypoxia. This approach has been found sensitive enough to detect not only the presence of the pulmonary vascular reactions but also qualitative differences in the responses to different substances.

While the x-ray record of induced pulmonary artery motion was similar after the selected drugs and hypoxia, there existed variations in the recovery time. With hypoxia and epinephrine, an immediate response occurred characterized by a rise in the pulmonary artery pressure and changes in the small arteries. When hypoxia was corrected and the pulmonary pressure response following epinephrine had subsided, $\mathrm{x}$-ray changes persisted in the small muscular arteries for as long as 15 minutes in both experiments. With metaraminol, the response persisted to a diminishing degree for an even longer period. The response to serotonin, on the other hand, disappeared when the compound was discontinued. This variation in the return of the small muscular arteries suggests differing mechanisms of action. It is possible that epinephrine and hypoxia response is mediated by the same reaction and would involve the response to catechol amines, hypoxia providing a strong stimulus for the discharge of this substance from the adrenergic tissues. Serotonin affects the smooth muscle, but the lung tissues possess a powerful enzymatic process for destroying its power of activation (Weissbach, Waalkes, and Udenfriend, 1957).

\section{SUMMARY}

The vasomotor activity of the pulmonary arteries was recorded by the technique of angiography in the dog. The contrast material was injected selectively via a catheter into the artery to be studied. Both the injection and $\mathrm{x}$-ray exposure were electronically programmed from the $\mathrm{R}$-wave of the electrocardiogram. Optimum dye injection and $\mathrm{x}$-ray viewing times were established. This precise X-ray viewing permitted comparisons of arteries 0.2 to $0.3 \mathrm{~mm}$. in diameter.

Respiration affected the "run-off" of the contrast material but not the size of the visualized pulmonary arteries. Epinephrine, 5-hydroxytryptamine, metaraminol, and eucapnic hypoxia caused segmental narrowing and gnarling of smaller arteries while the larger, proximal vessels passively dilated. Qualitative differences in induced pulmonary vasoconstriction occurred.

\section{REFERENCES}

Best, C. H., and Taylor, N. B. (1939). The Physiological Basis of Medical Practice, 2nd ed., p. 464. Williams and Wilkinson, London.

Boucek, R. J., Murphy, W. P., Jr., and Hernandez, F. A. (1961). Radiology, 76, 565.

Bradford, J. R., and Dean, H. P. (1894). J. Physiol. (Lond.), 16, 34.

Evans, W., Short, D. S., and Bedford, D. E. (1957). Brit. Heart J., 19, 93.

Fishman, A. P., Himmelstein, A., Fritts, H. W., Jr., and Cournand, A. (1955). J. clin. Invest., 34, 637

Fritts, H. W., and Cournand, A. (1959). The Pulmonary Circulation, ed. W. R. Adams and I. Veith, p. 63. Grune and Stratton, New York.

Heath, D., and Edwards, J. E. (1958). Circulation, 18, 533.

Johnson, J. B., Fairley, A., and Carter, C. (1959). Ann. intern. Med., 50, 34.

Kabins, S. A., Fridman, J., Neustadt, J., Espinosa, G., and Katz, L. N. (1960). Amer. J. Physiol., $198,543$.

Patel, D. J., and Burton, A. C. (1957). Circulat. Res., 5, 620.

- Lange, R. L., and Hecht, H. H. (1958). Circulation, 18, 19.

Rudolph, A. M., and Auld, P. A. M. (1960). Amer. J. Physiol., 198, 864

Shepherd, J. T., and Wood, E. H. (1959). Editorial. Circulation, 19, 641.

Short, D. S. (1957). Lancet, 2, 12.

Starling, E. H., and Evans, C. L. (1949). Human Physiology, 10th ed., p. 665. Lea and Febiger, London.

Weissbach, H., Waalkes, T. P., and Udenfriend, S. (1957). Science, 125, 235.

Wood, P., Besterman, E. M., Towers, M. K., and McIlroy, M. B. (1957). Brit. Heart J., 19, 279. 